\title{
ESTIMATION OF PULMONARY ARTERIOVENOUS SHUNT-FLOW USING INTRAVENOUS INJECTIONS OF T-1824 DYE AND KR ${ }^{85 *}$
}

\author{
By H. W. FRITTS, JR., A. HARDEWIG, D. F. ROCHESTER, J. DURAND AND \\ A. COURNAND \\ (From the Departments of Medicine and Surgery, Columbia University College of Physicians and \\ Surgeons, and the Cardio-Pulmonary Laboratory of the First Medical and Chest Services, \\ Columbia University Division, Bellevue Hospital, New York, N. Y.)
}

(Submitted for publication June 27, 1960; accepted August 11, 1960)

While the concept of venous admixture is simple, the pathways responsible for this entity are complex (1-4). They include a multiplicity of channels which can allow venous blood to reach the peripheral circulation: among them are congenital anomalies of the heart and great vessels; bronchial, Thebesian and anterior cardiac veins; portal-mediastinal-pulmonary venous anastomoses; and pulmonary arteriovenous shunts. This last pathway is of particular interest because such shunts are thought to develop in several common diseases of man. But no method has been available for assessing the flow which they carry. Hence, the argument for their importance has been based largely on inferential evidence.

This paper has two purposes. The first is to describe a method which will detect, and under certain conditions estimate, abnormal amounts of pulmonary arteriovenous shunt-flow. The second is to present the results obtained when the method was applied in patients with either pulmonary emphysema, pulmonary infection, or alcoholic cirrhosis of the liver, three conditions in which these shunts are said to occur.

\section{METHOD}

The method entails: $a$ ) dissolving a small volume of the inert, gaseous isotope $\mathrm{Kr}^{85}$ in $\mathrm{T}-1824$ dye, $b$ ) injecting a few cubic centimeters of this mixture into one of the great veins, and $c$ ) determining the ratio of dye to $\mathrm{Kr}^{85}$ concentrations in the systemic arteries during the initial passage of the indicators. Provided the patient is free of anomalies of the heart and great vessels, the ratio of concentrations depends on the partition of flow between alveolar capillaries and pulmonary arteriovenous shunts. The reasons for this dependence are depicted schematically in Figures 1,2 and 3.

\footnotetext{
* This investigation was supported by a research grant [H-2001 (C)] from the National Heart Institute, Bethesda, Md.
}

Figure 1 shows the concentration curves of dye and $\mathrm{Kr}^{85}$ in the blood leaving the alveolar capillaries. Because the dye remains in the blood stream, its curve has a characteristic contour which rises sharply, reaches a peak, and then declines. By way of contrast, more than 95 per cent of the $\mathrm{Kr}^{85}$ escapes into the alveoli (5), causing that remaining in solution to inscribe a curve which rises slowly to a maximum value occurring at about the point where manifest recirculation of dye appears.

Figure 2 compares the two curves when the indicators traverse pulmonary arteriovenous shunts. Since blood perfusing these channels is deprived of contact with alveolar gas, the $\mathrm{Kr}^{85}$ remains in the blood stream and the dye and $\mathrm{Kr}^{85}$ curves have similar forms.

Figure 3 depicts the curves obtained in the presence of both capillary and shunt pathways. In this situation the concentration of $\mathrm{Kr}^{85}$ in the common channel represents the sum of two components, namely, the sloping line from the capillaries and the peaked curve from the shunts.

\section{Calculations}

These considerations provide a background for estimating the pulmonary arteriovenous shuntflow, and, as a beginning, it will be temporarily
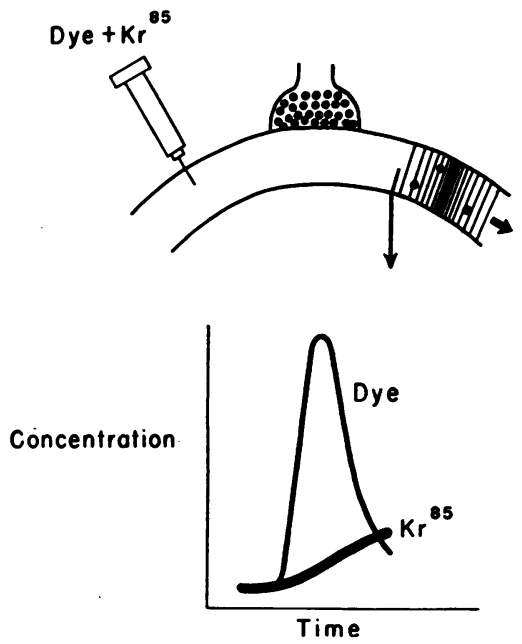

Fig. 1. Schematic DRAWING OF DYE AND $\mathrm{KR}^{85}$ CURVES in Blood LEaving alveolar Capillaries. Hatching represents dye, closed circles $\mathrm{Kr}^{85}$. 

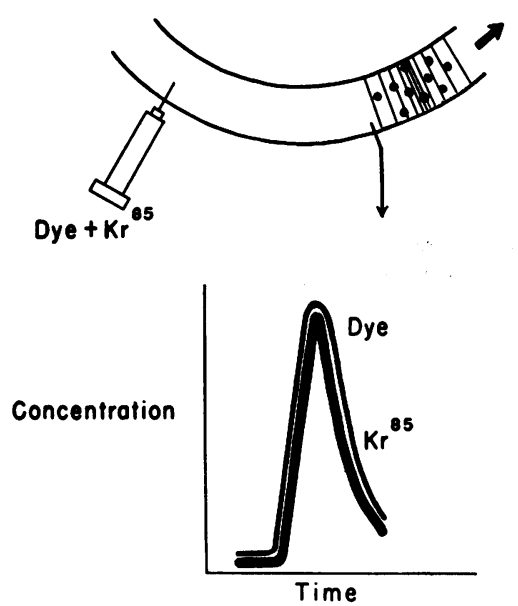

Fig. 2. Schematic DRAWING OF DYE AND $\mathrm{KR}^{85}$ CURVES IN BLOOD LEAVING PULMONARY ARTERIOVENOUS SHUNTS. Hatching represents dye, closed circles $\mathrm{Kr}^{85}$.

presumed that blood can be sampled at the point marked A in Figure 4. Thus, if blood is withdrawn at a constant rate during the first circulation of the indicators, the ratio of dye to $\mathrm{Kr}^{85}$ in the collected specimen is expressed by Equation 1.

$$
\frac{C c_{D}}{C c_{K}}=\frac{\int_{0}^{T} C a_{D} d t}{\int_{0}^{T} C a_{K} d t}
$$

where $\mathrm{C}_{\mathrm{D}}=$ concentration of dye in the specimen, $\mathrm{Cc}_{\mathrm{K}}=$ concentration of $\mathrm{Kr}^{85}$ in the specimen, $\mathrm{Ca}_{\mathrm{D}}=$ instantaneous concentration of dye in the vessel, $\mathrm{Ca}_{\mathrm{K}}=$ instantaneous concentration of $\mathrm{Kr}^{85}$ in the vessel and $\mathrm{T}=$ time during which blood is sampled. The numerator of the right hand member represents the sum of the contributions of dye from the alveolar and shunt pathways; the denominator represents the sum of the contributions of $\mathrm{Kr}^{85}$.

Assumptions of the method. The first assumption of the method is that the transit times of the alveolar and shunt pathways are equal. This assumption implies that the concentrations of dye in the blood leaving the two pathways are identical and equal to that in the confluent stream. By way of contrast, the concentration of $\mathrm{Kr}^{85}$ at the confluence can be described only by using the familiar mixing equation shown below.

$$
\mathrm{Ca}_{\mathrm{K}}=\frac{\dot{\mathrm{Q}}_{\mathrm{s}}}{\dot{\mathrm{Q}}_{\mathrm{p}}} \mathrm{Cs}_{\mathrm{K}}+\left(1-\frac{\dot{\mathrm{Q}}_{\mathrm{s}}}{\dot{\mathrm{Q}}_{\mathrm{p}}}\right) \mathrm{C}_{\mathrm{A}_{\mathrm{K}}}
$$

where $\mathrm{Cs}_{\mathrm{K}}=$ instantaneous concentration of $\mathrm{Kr}^{85}$ in the blood from the shunts, $\mathrm{CA}_{\mathbf{K}}=$ instantaneous concentration of $\mathrm{Kr}^{85}$ in the blood from the alveoli, $\dot{Q}_{s}=$ flow through shunts and $\dot{Q}_{p}=$ flow through the pulmonary artery. Substitution of Equation 2 in Equation 1 yields

$$
\frac{C c_{D}}{C c_{K}}=\frac{\int_{0}^{T} C a_{D} d t}{\int_{0}^{T}\left[\frac{\dot{Q}_{s}}{\dot{Q}_{p}} C s_{K}+\left(1-\frac{\dot{Q}_{s}}{\dot{Q}_{p}}\right) C A_{K}\right] d t} .
$$

With $\dot{Q}_{\mathrm{s}} / \dot{Q}_{\mathrm{p}}$ constant during the time of the first circulation, this relation can be simplified to Equation 3.

$$
\frac{C c_{D}}{C c_{K}}=\frac{\int_{0}^{T} C a_{D} d t}{\frac{\dot{Q}_{s}}{\dot{Q}_{p}} \int_{0}^{T} C s_{K} d t+\left(1-\frac{\dot{Q}_{s}}{\dot{Q}_{p}}\right) \int_{0}^{T} C_{A_{K} d t}}
$$

The second assumption of the method is that the ratio of concentrations of dye to $\mathrm{Kr}^{85}$ in the shunted blood is equal to the ratio of concentrations in the injectate. Hence

$$
\frac{\mathrm{C}_{\mathrm{D}}}{\mathrm{C}_{\mathrm{S}_{\mathrm{K}}}}=\frac{\mathrm{C}_{\mathrm{I}_{\mathrm{D}}}}{\mathrm{CI}_{\mathrm{K}}}
$$

or

$$
C s_{K}=\frac{C_{I_{K}}}{C_{I_{D}}} \cdot C s_{D}
$$
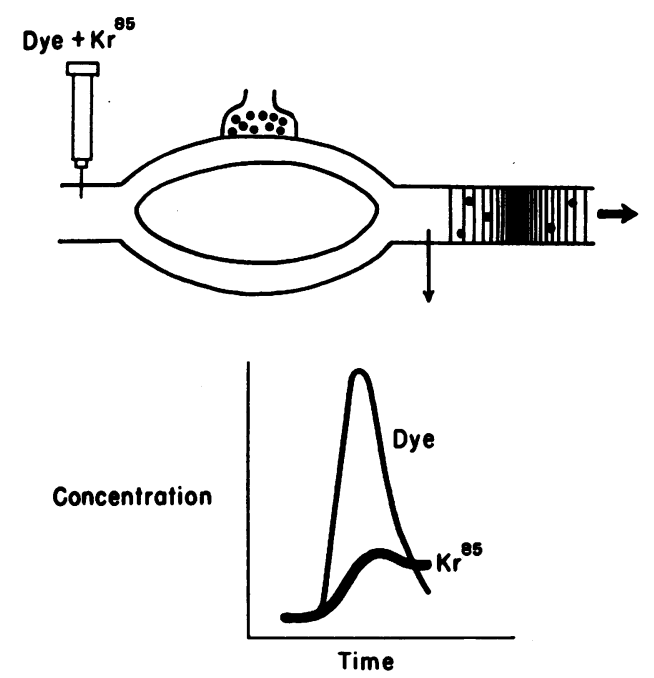

Fig. 3. SChEMATIC DRAWING OF DYE AND $\mathrm{KR}^{85}$ CURVES IN BLOOD AT CONFLUENCE OF STREAMS FROM ALVEOLAR CAPILLARIES AND PULMONARY ARTERIOVENOUS SHUNTS. Hatching represents dye, closed circles $\mathrm{Kr}^{85}$. 


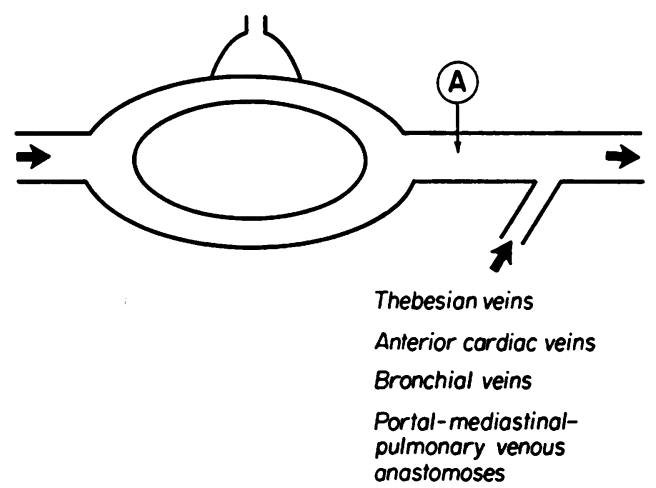

Fig. 4. Schematic DRAwing OF ALVEolar CapilLARIES, PULMONARY ARTERIOVENOUS SHUNTS, AND CHANNELS CARRYING VENOUS ADMIXTURE ORIGINATING FROM SITES OTHER THAN THE PULMONARY ARTERY.

where $\mathrm{CI}_{\mathbf{K}}=$ concentration of $\mathrm{Kr}^{85}$ in the injectate and $\mathrm{CI}_{\mathbf{D}}=$ concentration of dye in the injectate. Substitution of Equation 4 in Equation 3 yields

$$
\begin{aligned}
& \frac{C c_{D}}{C c_{K}} \\
& =\frac{\int_{0}^{T} C a_{D} d t}{\frac{\dot{Q}_{s}}{\dot{Q}_{p}} \cdot \frac{C_{I_{K}}}{C_{I_{D}}} \int_{0}^{T} C_{S_{D} d t}+\left(1-\frac{\dot{Q}_{s}}{\dot{Q}_{p}}\right) \int_{0}^{T} C_{A_{K}} d t}
\end{aligned}
$$

and, on the basis of the initial assumption that $\mathrm{Ca}_{\mathbf{D}}$ and $\mathrm{C}_{\mathbf{S}_{\mathrm{D}}}$ are equal, $\mathrm{Ca}_{\mathbf{D}}$ can be substituted for $\mathrm{Cs}_{\mathrm{D}}$ in Equation 5.

$$
\begin{aligned}
& \frac{C c_{D}}{C c_{K}} \\
& =\frac{\int_{0}^{T} C a_{D} d t}{\frac{\dot{Q}_{s}}{\dot{Q}_{p}} \cdot \frac{C I_{K}}{C I_{D}} \int_{0}^{T} C a_{D} d t+\left(1-\frac{\dot{Q}_{s}}{\dot{Q}_{p}}\right) \int_{0}^{T} C A_{K} d t} .
\end{aligned}
$$

Thus far the analysis has ignored the other sources of venous admixture, and it is now necessary to consider how the blood which they contribute influences the relation expressed in Equation 6. These sources, listed in Figure 4, convey venous blood into the pulmonary circulation or left heart chambers from vessels other than the pulmonary artery. Because this blood is free of dye and $\mathrm{Kr}^{85}$ during the initial passage of the indicators, it acts as a diluent and reduces the concentrations of dye and $\mathrm{Kr}^{85}$ equally. Hence, the ratio of concentrations of the indicators is insensitive to its presence, and the relation expressed in Equation 6 is unchanged. Similar reasoning can be applied to the blood contained in the left atrium and ventricle. Since this too acts as a diluent, Equation 6 is valid not only for a blood specimen collected at point $A$, but for a specimen withdrawn from a brachial artery, the usual sampling site.

The third assumption of the method is that the $\mathrm{Kr}^{85}$ in the blood leaving the alveolar limb describes a curve which, during the time of sampling, is an approximately linear function of time. This allows $\mathrm{C}_{\mathrm{A}_{\mathrm{K}}}$ to be expressed as shown in Equation 7.

$$
\mathrm{CA}_{\mathrm{K}}=\mathrm{Kt}
$$

where $\mathrm{K}=$ the slope of the line.

Substitution of Equation 7 in Equation 6 yields Equation 8.

$$
\begin{aligned}
& \frac{C c_{D}}{C c_{K}} \\
& =\frac{\int_{0}^{T} C a_{D} d t}{\frac{\dot{Q}_{s}}{\dot{Q}_{p}} \cdot \frac{C I_{K}}{C I_{D}} \int_{0}^{T} C a_{D} d t+\left(1-\frac{\dot{Q}_{s}}{\dot{Q}_{p}}\right) K \int_{0}^{T} t d t} .
\end{aligned}
$$

Equation 8 contains two unknown quantities: $\dot{Q}_{\mathrm{s}} / \dot{\mathrm{Q}}_{\mathrm{p}}$, the fraction of the pulmonary arterial flow traversing shunts, and $K$, the slope of the straight line. While the presence of two unknowns renders a straightforward solution of the equation impossible, a solution can be obtained

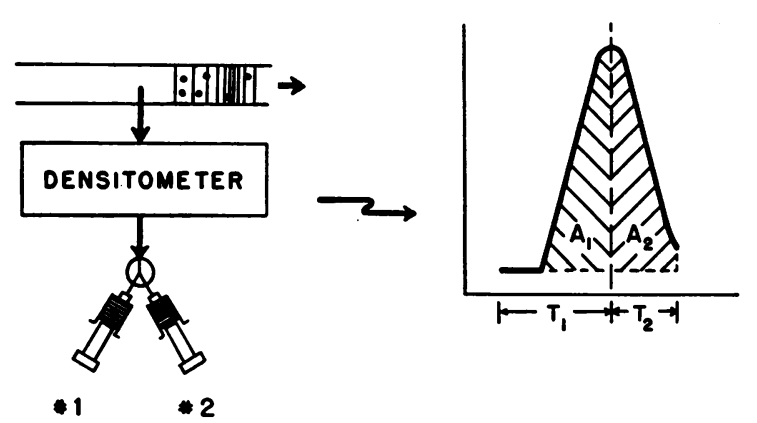

Fig. 5. Schematic dRAWING OF METhOd USEd to COLLECT TWO SAMPLES OF ARTERIAL BLOOD DURING THE FIRST CIRCULATION OF THE INDICATORS. The densitometer inscribes the dye curve directly on an oscilloscopic screen. Syringe no. 1 samples during period $T_{1}$, and syringe no. 2 during period $\mathrm{T}_{2}$. 
if arterial blood samples are collected into two syringes connected as shown in Figure 5. Syringe no. 1 samples blood through the densitometer from the time of injection to the approximate peak of the dye curve; syringe no. 2 samples from the peak of the curve to some point on the downslope before obvious recirculation of dye appears. Analyses of these two specimens for dye and $\mathrm{Kr}^{85}$ concentrations allow Equation 8 to be written for two different situations. Thus, for syringe no. 1

$$
\begin{aligned}
& {\left[\frac{C c_{D}}{C c_{K}}\right]_{1}} \\
& =\frac{\int_{0}^{T_{1}} C a_{D} d t}{\frac{\dot{Q}_{s}}{\dot{Q}_{p}} \cdot \frac{C I_{K}}{C_{I_{D}}} \int_{0}^{T_{1}} C a_{D} d t+\left(1-\frac{\dot{Q}_{s}}{\dot{Q}_{p}}\right) K \cdot \frac{T_{1}^{2}}{2}}
\end{aligned}
$$

and for syringe no. 2

$$
\left[\frac{C c_{\mathrm{D}}}{\mathrm{C} \mathrm{c}_{\mathrm{K}}}\right]_{2}=\frac{\int_{\mathrm{T}_{1}}^{\mathrm{T}_{2}} \mathrm{Ca}_{\mathrm{D}} \mathrm{dt}}{\frac{\dot{\mathrm{Q}}_{\mathrm{s}}}{\dot{\mathrm{Q}}_{\mathrm{p}}} \cdot \frac{\mathrm{CI}_{\mathrm{K}}}{\mathrm{CI}_{\mathrm{D}}} \int_{\mathrm{T}_{1}}^{\mathrm{T}_{2}} \mathrm{Ca} \mathrm{d} \mathrm{t}+\left(1-\frac{\dot{\mathrm{Q}}_{\mathrm{s}}}{\dot{\mathrm{Q}}_{\mathrm{p}}}\right) \mathrm{K}\left(\frac{\mathrm{T}_{2}{ }^{2}-\mathrm{T}_{1}^{2}}{2}\right)} .
$$

The simultaneous solution of these two equations provides an expression for $\dot{Q}_{\mathrm{s}} / \dot{\mathrm{Q}}_{\mathrm{p}}$.

$$
\frac{\dot{Q}_{\mathrm{s}}}{\mathrm{Q}_{\mathrm{p}}}=\frac{\left[\frac{\mathrm{C} \mathrm{C}_{\mathrm{K}}}{\mathrm{Cc_{ \textrm {D } }}}\right]_{1}\left(\mathrm{~T}_{2}{ }^{2}-\mathrm{T}_{1}{ }^{2}\right) \int_{0}^{\mathrm{T}_{1}} \mathrm{Ca} \mathrm{d} \mathrm{t}-\left[\frac{\mathrm{C} \mathrm{C}_{\mathrm{K}}}{\mathrm{C}_{\mathrm{D}}}\right]_{2}\left(\mathrm{~T}_{1}{ }^{2}\right) \int_{\mathrm{T}_{1}}^{\mathrm{T}_{2}} \mathrm{Ca} \mathrm{d} \mathrm{t}}{\left[\frac{\mathrm{CI}_{\mathrm{K}}}{\mathrm{CI}_{\mathrm{D}}}\right]\left[\left(\mathrm{T}_{2}{ }^{2}-\mathrm{T}_{1}{ }^{2}\right) \int_{0}^{\mathrm{T}_{1}} \mathrm{Ca} \mathrm{dt}-\mathrm{T}_{1}{ }^{2} \int_{\mathrm{T}_{1}}^{\mathrm{T}_{2}} \mathrm{CaDdt}\right]} .
$$

Each integral can be evaluated by first measuring the corresponding area shown in Figure 5 and then multiplying this value by a calibrating factor, M, which converts the area to the product of concentration and time. Thus

$$
\begin{aligned}
& \int_{0}^{T_{1}} C a_{D} d t=M A_{1} \\
& \int_{T_{1}}^{T_{2}} C a_{D} d t=M A_{2} .
\end{aligned}
$$

Since, however, an integral appears in each of the terms of the numerator and denominator of Equation 11, the necessity for calibrating the curves is obviated, and the solution of the equation is simplified by substituting the areas for the integrals which they represent.

$\frac{\dot{Q}_{\mathrm{s}}}{\dot{Q}_{\mathrm{p}}}$

$$
=\frac{\left[\frac{\mathrm{C}_{\mathrm{K}}}{\mathrm{C}_{\mathrm{D}}}\right]_{1}\left(\mathrm{~T}_{2}^{2}-\mathrm{T}_{1}^{2}\right) \mathrm{A}_{1}-\left[\frac{\mathrm{C} \mathrm{c}_{\mathrm{K}}}{\mathrm{C}_{\mathrm{D}}}\right]_{2}\left(\mathrm{~T}_{1}^{2}\right) \mathrm{A}_{2}}{\left[\frac{\mathrm{CI}_{\mathrm{K}}}{\mathrm{CI}_{\mathrm{D}}}\right]\left[\left(\mathrm{T}_{2}^{2}-\mathrm{T}_{1}^{2}\right) \mathrm{A}_{1}-\mathrm{T}_{1}^{2} \mathrm{~A}_{2}\right]} .
$$

Finally, the calculated value of $\dot{Q}_{\mathrm{s}} / \dot{\mathrm{Q}}_{\mathrm{p}}$ can be used in conjunction with Equation 9 to obtain a solution for $\mathrm{K}$.

$$
K=\frac{\int_{0}^{\mathrm{T}_{1}} C a_{D} d t-\left[\frac{C c_{D}}{C c_{K}}\right]_{1}\left[\frac{\dot{Q}_{s}}{\dot{Q}_{p}}\right]\left[\frac{C I_{K}}{C I_{D}}\right] \int_{0}^{T_{1}} C a_{D} d t}{\left[\frac{C c_{D}}{C c_{K}}\right]_{1}\left(1-\frac{\dot{Q}_{s}}{\dot{Q}_{p}}\right) \frac{T_{1}^{2}}{2}} .
$$

In this equation the time integral of the concentration of dye appears only in the terms of the numerator, and. for this reason, the corresponding areas cannot be substituted as in Equation 12 unless the calibration factor $\mathrm{M}$ is applied.

$$
\mathrm{K}=\frac{\mathrm{MA}_{1}\left\{1-\left[\frac{\mathrm{C}_{\mathrm{D}}}{\mathrm{C}_{\mathrm{K}}}\right]_{1}\left[\frac{\dot{\mathrm{Q}}_{\mathrm{s}}}{\dot{\mathrm{Q}}_{\mathrm{p}}}\right]\left[\frac{\mathrm{CI}_{\mathrm{K}}}{\mathrm{CI}_{\mathrm{D}}}\right]\right\}}{\left[\frac{\mathrm{C}_{\mathrm{D}}}{\mathrm{C}_{\mathrm{K}}}\right]_{1}\left(1-\frac{\dot{\mathrm{Q}}_{\mathrm{s}}}{\dot{\mathrm{Q}}_{\mathrm{p}}}\right) \frac{\mathrm{T}_{1}^{2}}{2}} .
$$

One further relation has considerable importance. This is the ratio $\mathrm{R}$ which defines the slope $\mathrm{K}$ per unit of radioactivity injected.

$$
\mathrm{R}=\frac{\mathrm{K}}{\left(\mathrm{C}_{\mathrm{K}}\right)\left(\mathrm{V}_{\mathrm{I}}\right)}
$$

where $V_{I}=$ volume of dye injected. The usefulness of this ratio will be considered in the next section. 
The units of the quantities included in the foregoing equations are tabulated below. If the concentrations of dye are read in plasma, the numbers must be converted to whole blood values by multiplying each by 1 -hematocrit.

$\begin{array}{ll}\mathrm{Cc}_{K} \text { and } \mathrm{CI}_{K} & \text { counts/cuvet/minute } \\ \mathrm{Cc}_{\mathrm{D}} \text { and } \mathrm{CI}_{\mathrm{D}} & \mathrm{mg} / \mathrm{cc} \\ \mathrm{T}_{1} \text { and } \mathrm{T}_{2} & \text { seconds } \\ \mathrm{A}_{1} \text { and } \mathrm{A}_{2} & \mathrm{~cm}^{2} \\ \mathrm{~K} & (\text { counts/cuvet } / \text { minute }) / \text { second } \\ \mathrm{M} & {[(\mathrm{mg})(\mathrm{sec}) / \mathrm{L}] / \mathrm{cm}^{2}} \\ \mathrm{~V}_{\mathrm{I}} & \mathrm{cc}\end{array}$

Evaluation of the assumptions. As mentioned in the preceding section, the validity of the method rests on three major assumptions. The first is that the transit times through the alveolar and shunt pathways are equal. Such equality would be expected with multiple, small pulmonary arteriovenous fistulas, and, to confirm this expectation, we drew two $\mathrm{Kr}^{85}$ curves in each of two patients in whom such fistulas had been demonstrated by angiography. The curves were constructed by collecting sequential small anaerobic samples of blood from a manifold connected to the needle in the brachial artery. One of the curves, typical of all of them, is shown in Figure 6A. Inspection of the figure reveals that the $\mathrm{Kr}^{85}$ curve was approximately in phase with the dye curve; this phase correspondence suggests that in these two patients the first assumption of the method was met.

But the validity of the assumption is less certain in patients with large fistulas connecting the major pulmonary vessels near the hila of the lungs. While the construction of a $\mathrm{Kr}^{85}$ curve in each such patient is not practical, the validity of the assumption can still be tested in two ways. The first is the appearance of the dye curve: with a large shunt having a short transit time, a break in the curve may appear (6). The second safeguard is the ratio $R$ defined by Equation 15. If the transit time of blood through the shunt is shorter than that through the capillaries, $\mathrm{R}$ will have a large negative value. While in those patients failing to fulfill the assumption the estimation of shunt-flow is not possible, the method will nevertheless indicate that such shunts exist.

The second assumption of the method, based on the belief that during the first circulation the $\mathrm{Kr}^{85}$ remains in the blood conveyed by shunts, is that the ratio of concentrations of dye to $\mathrm{Kr}^{85}$ in this blood is the same as that in the injectate. While this hypothesis could not be directly tested for shunts in the pulmonary circulation, we indirectly evaluated its validity by injecting a solution of dye and $\mathrm{Kr}^{85}$ into a brachial vein while collecting a blood sample from the pulmonary artery during the time of the initial circulation of the indicators. Such studies were carried out in four patients. In each, the ratio of dye to $\mathrm{Kr}^{85}$ in the sample was almost identical to that in the injectate.

The third assumption is that the blood leaving the alveofar limb describes an arterial concentration curve which is

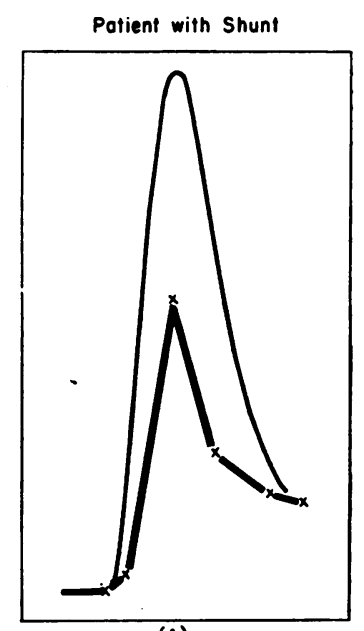

(A)

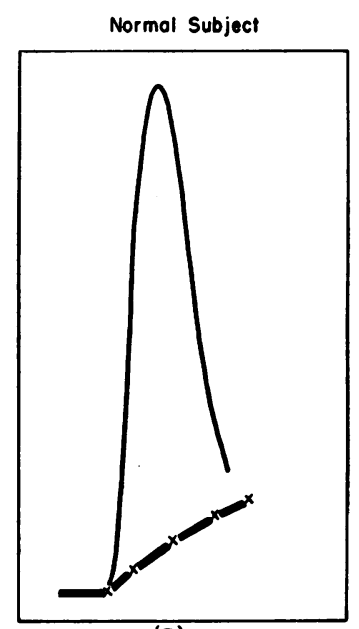

(B)
Fig. 6. Comparison of time Relation OF dye (CONTINUOUS LINE) AND $\mathrm{KR}^{85}$ (BROKEN LINE) CURVES IN PATIENTS WITH AND WITHOUT PULMONARY ARTERIOVENOUS shunts. Time is plotted on the horizontal axis, and concentrations of the indicators on the vertical axis. For explanation of the construction of the curves, see text.

an approximately linear function of time. The validity of this premise is supported by two lines of evidence. The first is theoretical and comes from graphic constructions of the concentrations of $\mathrm{Kr}^{85}$ in blood leaving the alveolar capillaries after a bolus of the isotope has been rapidly injected into one of the great veins. With such an injection, the concentration of $\mathrm{Kr}^{85}$ entering the capillaries resembles either a step function or a tall triangle, and by using a modified Bohr integration, one can show that the concentration leaving the capillaries has a sigmoid relation to time. While the exact shape depends on the configuration of the bolus, the deviations from linearity of the early portions of the sigmoid curves are small.

The other line of evidence comes from curves actually drawn in eight normal subjects; a typical example is shown in Figure 6B. In such subjects the pulmonary arteriovenous shunt-flow is known to be minimal (7-9), and, as expected, the curves approximated straight lines.

A fourth assumption, implied but not previously mentioned, is that the method is insensitive to the other factors that can lower the saturation of the arterial blood. These factors include inadequate ventilation, disturbed ventilation-perfusion relationships, impaired diffusion, and abnormal hemoglobin. None of these factors directly affects the dye curve, and none influences the $\mathrm{Kr}^{85}$ curve to any great extent. For instance, inadequate ventilation and disturbed ventilation-perfusion ratios are of less importance during the brief initial passage of the indicators than are the volumes of air contained in the alveoli contacted by the $\mathrm{Kr}^{85}$-carrying blood. To investigate the effect of different lung volumes, we drew successive curves in six normal subjects while they held their breaths at different fractions of the vital capacity. Whereas the slopes of the $\mathrm{Kr}^{85}$ curves decreased with increasing lung volumes, the linearity of the curves was not_affected. 
Although a reduced diffusing capacity may influence the arterial $\mathrm{Kr}^{85}$ concentration, a moderately thickened membrane should be of only small consequence since inert gases reach equilibrium so rapidly.

Finally, abnormal hemoblobin can probably be discounted because $\mathrm{Kr}^{85}$ is believed to be carried in simple physical solution in both the plasma and the cells.

Procedure in patients. The details of preparing the solutions for injection have been published previously (5). In the present study, the concentrations of dye and $\mathrm{Kr}^{85}$ were adjusted so that each cubic centimeter of dye contained approximately $50 \mu \mathrm{c}$ of radioactivity.

All patients were studied in the fasting, basal state. A small polyethylene catheter was advanced through an antecubital vein until the catheter tip lay in the axillary vein. A Cournand needle was inserted into the right brachial artery.

The experimental procedure was started after the patient

TABLE I

Measured values of arterial oxygen saturation $\left(S_{\mathrm{aO}_{2}}\right)$ and calculated values of shunt-flow $\left(\dot{Q}_{s} / \dot{Q}_{p}\right)$

\begin{tabular}{|c|c|c|c|}
\hline Subject & Diagnosis & $\mathrm{SaO}_{2}$ & $\dot{\mathrm{Q}}_{\mathrm{s}} / \dot{\mathrm{Q}}_{\mathrm{p}}$ \\
\hline \multirow{9}{*}{\multicolumn{2}{|c|}{ Group I: Control subjects }} & $\%$ & $\%$ \\
\hline & & 97 & $<1$ \\
\hline & & 96 & $<1$ \\
\hline & & 95 & $<1$ \\
\hline & & 95 & $<1$ \\
\hline & & 95 & $<1$ \\
\hline & & 95 & $<1$ \\
\hline & & 94 & $<1$ \\
\hline & & 94 & $<1$ \\
\hline \multicolumn{4}{|c|}{ Group II : Patients with pulmonary emphysema } \\
\hline A.S. & & 92 & $<1$ \\
\hline J.W. & & 92 & $<1$ \\
\hline L.B. & & 91 & $<1$ \\
\hline J.G. & & 90 & $<1$ \\
\hline W.D. & & 89 & $<1$ \\
\hline S.V. & & 86 & $<1$ \\
\hline M.W. & & 85 & $<1$ \\
\hline H.G. & & 81 & 2 \\
\hline \multicolumn{4}{|c|}{ Group III : Patients with pulmonary infections } \\
\hline T.D. & Chronic bronchitis & 91 & $<1$ \\
\hline J.Q. & Chronic bronchit is & 88 & 2 \\
\hline B. B. & Bronchiectasis & 90 & $<\overline{1}$ \\
\hline W.P. & Bronchiectasis & 93 & $<1$ \\
\hline J.B. & Unresolved pneumonia & 92 & $<1$ \\
\hline C.T. & Unresolved pneumonia & 87 & $<1$ \\
\hline E.Mc. & Advanced pulmonary tuberculosis & 91 & $<1$ \\
\hline E.D. & Advanced pulmonary tuberculosis & 90 & $<1$ \\
\hline W.B. & Advanced pulmonary tuberculosis & 89 & $<1$ \\
\hline H.P. & Advanced pulmonary tuberculosis & 78 & 2 \\
\hline \multirow{3}{*}{$\begin{array}{l}\text { A. B. } \\
\text { L.P. }\end{array}$} & Advanced pulmonary tuberculosis & 77 & $<1$ \\
\hline & Advanced pulmonary tuberculosis and & & . \\
\hline & alcoholic cirrhosis of the liver & 88 & 8 \\
\hline \multicolumn{4}{|c|}{ Group IV: Patients with alcoholic cirrhosis of the liver } \\
\hline J.R. & & 97 & $<1$ \\
\hline P.K. & & 95 & $<1$ \\
\hline P.B. & & 95 & $<1$ \\
\hline C.K. & & 94 & $<1$ \\
\hline J.K. & & 94 & $<1$ \\
\hline A.M. & & 92 & $<1$ \\
\hline W.K. & & 90 & $<1$ \\
\hline F.M. & & 90 & 3 \\
\hline R.W. & & 90 & 2 \\
\hline W.D. & & 89 & $<\overline{1}$ \\
\hline J.P. & & 89 & 2 \\
\hline A. & & 88 & $<\overline{1}$ \\
\hline A.A. & & $\begin{array}{l}83 \\
79\end{array}$ & $<1$ \\
\hline \multicolumn{4}{|c|}{ Group V: Patients with Weber-Rendu-Osler's disease } \\
\hline M.S. & & 94 & 12 \\
\hline J.L. & & 91 & 9 \\
\hline J.P. & & 72 & 57 \\
\hline
\end{tabular}

had rested for 15 minutes with the catheter and needle in place. The patient breathed through a mouthpiece which connected him to an open breathing circuit. After 5 minutes of quiet breathing, $3 \mathrm{cc}$ of the dye and $\mathrm{Kr}^{85}$ mixture was rapidly injected into the catheter while arterial blood was withdrawn at a constant rate through a Colson densitometer into the syringe designated no. 1 in Figure 5. Near the peak of the curve, the stopcock was turned and syringe no. 2 continued the sampling to a point on the downslope short of obvious recirculation of dye. Each of the collected samples was thoroughly mixed, then divided into two parts: one was used to determine the concentration of dye in plasma, the other was used to assay the radioactivity in hemolyzed blood.

The concentration of radioactivity in each of the blood specimens was measured by the method of Lassen and Munck (10). For this measurement the hemolyzed sample was transferred to an air-tight, disc-shaped cuvet of $1.5 \mathrm{cc}$ volume, and the radioactivity emitted from each face was counted with a Geiger-Mueller tube. These counts, made simultaneously, were summed by one scaler. Each count was continued for a sufficiently long period to insure that the statistical error was less than 5 per cent.

Dye concentrations were read in plasma, using a Beckman Model DU spectrophotometer.

Arterial blood oxygen saturations were determined by the method of Van Slyke and Neil.

Patient material. Five groups of patients were studied. The arterial saturation of each patient is recorded in Table I.

The first group comprised 8 men and women who were either healthy or who had minimal apical tuberculosis. These subjects served as controls.

The second group included 8 patients with clinical, roentgenological and physiological stigmata of advanced pulmonary emphysema.

The third group was composed of 12 men and women with pulmonary infections, including chronic bronchitis, bronchiectasis, unresolved pneumonia, and advanced pulmonary tuberculosis. Many of these patients had $\mathrm{X}$-ray evidence of widespread pulmonary fibrosis.

The fourth group embraced 14 patients with alcoholic cirrhosis of the liver. Although none had evidence of heart or lung disease, 9 had arterial saturations below 94 per cent.

The fifth group was made up of 1 man and 2 women with Weber-Rendu-Osler's disease. Each had a low arterial saturation, and each had had one or more pulmonary arteriovenous fistulas demonstrated by angiography.

\section{RESULTS}

The results are presented in Table I. The shunts calculated in the normal subjects were in some instances slightly negative due, presumably, to the fact that the $\mathrm{Kr}^{85}$ curves are sigmoids rather than absolutely straight lines. In no subject, however, was the magnitude of the calculated shunt greater than 1 per cent of the flow through the pulmonary artery. 
Seven of the patients with emphysema had values which were no different from those calculated in the normals; the eighth (H. G.) had an estimated shunt-flow of 2 per cent.

Nine of the patients with pulmonary infections had values of shunt-flows within the normal range, while three (J. Q., H. P. and L. P.) had values of 2, 2 and 8 per cent, respectively.

Eleven of the patients with cirrhosis had shunt-flows of less than 1 per cent, two had 2 per cent, and one had 3 per cent.

By way of contrast, the patients with WeberRendu-Osler's disease had shunts between 9 and 57 per cent. Thus, only in these patients did shunts appear to account for the levels of saturation in the arterial blood.

The ratio $\mathrm{R}$ was calculated for each patient studied. With a single exception, there was no difference between the values found in the normal subjects and those calculated in the patient groups. The average for the normals was $\mathbf{1 2 . 2}$ with a standard deviation of 7.7. Further, these values agreed with the average value of $12.6 \pm 5.7$ obtained in eight normal subjects in whom the curves of $\mathrm{Kr}^{85}$ concentration were actually drawn. The only exception was a case of Weber-Rendu-Osler's disease with large anastomoses near the hila of the lungs. The value of $\mathrm{R}$ in this patient was $-1,500$, suggesting that the transit times through the shunts were shorter than those through the capillaries. The appearance of the dye curve supported this belief; instead of having a smooth contour, the curve showed two distinct peaks.

\section{DISCUSSION}

Advantages and disadvantages of the method. The major advantage of the method is its specificity for detecting the presence of pulmonary arteriovenous shunts (11). Previous techniques have not clearly distinguished between the flow through pulmonary arteriovenous connections and other sources of venous blood. Recently, Jose and Milnor (12) have used the Valsalva maneuver to demonstrate the presence of shunting, but have carefully emphasized that a shunt can be mimicked by severe ventilation-perfusion disturbances. Recently also Braunwald, Long and Morrow (13), as well as Long, Waldhausen, Cornell and Sanders (14), have used intravenous injections of $\mathrm{Kr}^{85}$ alone to demonstrate that pulmonary arteriovenous shunts exist.

The second advantage of the method resides in the fact that it is not influenced by the level of the arterial saturation, nor does it require that this level be changed. This point is of particular importance in patients with emphysema in whom the administration of oxygen may alter the distribution of blood flow in the lungs.

The chief disadvantage stems from the assumption that the curves of $\mathrm{Kr}^{85}$ in blood perfusing alveoli are linear. This premise imposes the greatest handicap when shunts carry only a small proportion of the pulmonary arterial blood flow, and, for this reason, the method is not suitable for estimating the shunt-flow existing in normal man. That the estimates of larger shunt-flows are more reliable is suggested by the results in the patients with Weber-Rendu-Osler's disease. In these patients, the calculated shunts were compatible with the levels of saturation measured in the arterial blood.

A second disadvantage exists because $\mathrm{Kr}^{85}$ and oxygen have different solubilities in the pulmonary membrane. Hence, a vessel might serve as a shunt for oxygen and not for $\mathrm{Kr}^{85}$.

Results in patients with pulmonary diseases. The fact that shunts were not found in the patients with emphysema or with pulmonary infections does not rule out the possibility that in some patients with these diseases such shunts exist. Emphysema in particular is characterized by its protean manifestations, and it is conceivable that shunts sometimes occur in this complex disease. However, others have published data which make the invariable presence of sizable shunts unlikely (15). In addition, recent studies have provided evidence that the arterial unsaturation in patients with this disorder can be satisfactorily explained by ventilation-perfusion disturbances alone (16-18).

Without question, some patients with emphysema fail to achieve the expected arterial oxygen content when they breathe oxygen, a phenomenon generally attributed to the shunting of venous blood. An alternative explanation may lie in the behavior of those alveoli which are grossly underventilated; these have tensions of oxygen so close to that of the venous blood entering the capillaries that the exchange of gas is 
TABLE II

Comparison of average ratios of mixed venous $\left(C_{\bar{v}}\right)$ and brachial arterial $\left(C_{\mathrm{a}}\right)$ blood concentrations of $K r^{85}$ when the isotope was infused first into the duodenum and then into the right atrium

\begin{tabular}{lcc}
\hline & $\begin{array}{c}\mathrm{C}_{\bar{v}} / \mathrm{C}_{\mathrm{a}} \\
\text { during } \\
\text { duodenal } \\
\text { infusion }\end{array}$ & $\begin{array}{c}\mathrm{C}_{\overline{\mathrm{v}}} / \mathrm{C}_{\mathrm{s}} \\
\text { during } \\
\text { right atrial } \\
\text { infusion }\end{array}$ \\
\hline 4 Normal subjects & 11.9 & 11.5 \\
5 Patients with cirrhosis & 5.5 & 14.0 \\
\hline
\end{tabular}

minimized to the point where these capillaries serve as pulmonary arteriovenous shunts. But the reduced ventilation should not prevent the escape of $\mathrm{Kr}^{85}$ during its initial passage through these vessels. Thus, the oxygen and $\mathrm{Kr}^{85}$ methods probably detect different anatomic pathways; the former includes all channels in which gas exchange is minimal, while the latter detects that fraction of these channels deprived of contact with alveolar gas.

Results in patients with alcoholic cirrhosis of the liver. Although the fact that patients with cirrhosis are sometimes cyanotic has been recognized for almost a century (19), the cause of the cyanosis is not yet known. In 1938 Keys and Snell (20) suggested that the fundamental affinity of hemoglobin for oxygen is reduced in cirrhosis, but Jandl (21) later questioned this view. More recently, Abelmann and his co-workers (22) and Heinemann, Emirgil and Mijnssen (23) have shown that an augmented venous admixture is at least partially at fault. In this connection, Rydell and Hoffbauer (24) demonstrated multiple, small pulmonary arteriovenous fistulas in a young man with juvenile cirrhosis, and suggested that shunting through these channels accounted for the cyanosis which existed during life. While this observation has led others to invoke the same mechanism in patients with alcoholic disease of the liver, the results of the present study appear to rule out the possibility that direct connections between the pulmonary artery and the pulmonary veins invariably account for the lowered saturation of the arterial blood.

An alternative explanation, previously implied by McIndoe (25) and by Schoenmackers and Vieten (26), has recently been investigated by Calabresi and Abelmann (27). From injection studies performed at autopsy, these last investigators adduced evidence that patients with Laennec's cirrhosis have vascular anastomoses which connect the portal circulation to the pulmonary veins. To investigate whether these channels carry blood in living humans, we studied five patients with alcoholic cirrhosis and four normal subjects, using a technique which entailed catheterization of the pulmonary artery, cannulation of the brachial artery, and installation of a Levine tube in the duodenum. $\mathrm{Kr}^{85}$ was first introduced into the portal circulation by infusing a solution of this gas into the duodenum through the Levine tube. Since preliminary observations had indicated that this procedure produced steady concentrations of $\mathrm{Kr}^{85}$ in the arterial and mixed venous blood streams for periods of from 5 to 9 minutes, blood samples were simultaneously collected from the pulmonary and brachial arteries at 1-minute intervals during this time. The patient then rested quietly until all of the $\mathrm{Kr}^{85}$ had been eliminated via his expired gas. In a second run, an infusion of $\mathrm{Kr}^{85}$ was directed into the right atrium and samples of arterial and venous blood were again obtained. The concentrations of $\mathrm{Kr}^{85}$ in the collected blood specimens were measured. The results are summarized in Table II.

In the four normal subjects, the ratios of venous to arterial concentrations were approximately the same for each route of administration. By way of contrast, the five cirrhotic patients had smaller ratios when the $\mathrm{Kr}^{85}$ was introduced into the duodenum than when it was infused into the right atrium. Since none of the patients manifested a pulmonary arteriovenous shunt when tested by the single injection method, the smaller ratios suggest that blood from the portal veins entered the pulmonary vessels beyond the capillary bed. While these observations support the belief that portal-mediastinal-pulmonary connections contributed to the unsaturation, they do not provide indisputable evidence that these connections were the sole cause. In the first place, the method will not allow a quantitative estimate of the blood flowing through these channels. Secondly, on the basis of the blood oxygen saturation found in the portal circulation by Smythe, Fitzpatrick and Blakemore (28), the volume of anastomotic flow necessary to lower the arterial saturation to the level seen in some patients with cirrhosis would have to be a 
remarkably large fraction of the flow delivered to the entire splanchnic bed.

\section{SUMMARY}

The intravenous injection of $\mathrm{Kr}^{85}$ dissolved in T-1824 dye provides a method for estimating the fraction of the pulmonary arterial blood flow perfusing arteriovenous shunts. As expected, large shunts were present in patients with WeberRendu-Osler's disease who exhibited arterial blood oxygen unsaturation. By way of contrast, no sizable shunts were evident in 8 patients with pulmonary emphysema or in 12 patients with pulmonary infections. Further, only small shunts were found in 14 patients with Laennec's cirrhosis, even though 9 of these patients had arterial saturations below 94 per cent. Additional studies on 5 of these patients suggested that vascular anastomoses connected the portal bed with the post-capillary segments of the pulmonary vessels. These studies did not reveal the size of the flow through the anastomoses, nor whether this flow fully accounted for the reduced saturation of the arterial blood.

\section{ACKNOWLEDGMENT}

We are indebted to Dr. Israel Steinberg, Dr. Putnam Lloyd and Dr. Bella Strauss for allowing us to study their patients with Weber-Rendu-Osler's disease.

\section{REFERENCES}

1. Lilienthal, J. L., Jr., Riley, R. L., Proemmel, D. D., and Franke, R. E. An experimental analysis in man of the oxygen pressure gradient from alveolar air to arterial blood during rest and exercise at sea level and at altitude. Amer J. Physiol. 1946, 147, 199.

2. Riley, R. L., Lilienthal, J. L., Jr., Proemmel, D. D., and Franke, R. E. On the determination of physiologically effective pressures of oxygen and carbon dioxide in alveolar air. Amer. J. Physiol. 1946, 147, 191.

3. Rahn, H. A concept of mean alveolar air and the ventilation-bloodflow relationships during pulmonary gas exchange. Amer. J. Physiol. 1949, 158, 21.

4. Riley, R. L., and Cournand, A. Analysis of factors affecting partial pressures of oxygen and carbon dioxide in gas and blood of lungs: Theory. J. appl. Physiol. 1951, 4, 77.

5. Chidsey, C. A., III, Fritts, H. W., Jr., Hardewig, A., Richards, D. W., and Cournand, A. Fate of radioactive krypton $\left(\mathrm{Kr}^{85}\right)$ introduced intravenously in man. J. appl. Physiol. 1958, 14, 63.
6. Callahan, J. A., Helmholz, H. F., Jr., and Kirklin, J. W. Pulmonary arteriovenous fistula located by indicator dilution studies. Amer. Heart J. 1956, $52,916$.

7. Berggren, S. M. The oxygen deficit of arterial blood caused by nonventilating parts of lung. Acta physiol. scand. 1942, 4, 11, suppl. 1.

8. Bartels, H., and Rodewald, G. Die alveolär-arterielle Sauerstoffdruckdifferenz und das Problem des Gasaustausches in der menschlichen Lunge. Pflug. Arch. ges. Physiol. 1953, 258, 163.

9. Bartels, H., Bücherl, E., Mochizuki, M., and Niemann, G. Bestimmung der via venae thebesii in den linken Ventrikel fliessenden Blutmenge durch Messung des $\mathrm{O}_{2}$-Druckes im Blut des linken Vorhofs und einer Arterie beim Menschen. Pflug. Arch. ges. Physiol. 1956, 262, 478.

10. Lassen, N. A., and Munck, O. The cerebral blood flow in man determined by the use of radioactive krypton. Acta physiol. scand. 1955, 33, 30.

11. Fritts, H. W., Jr., Hardewig, A., Rochester, D., and Durand, J. Detection of pulmonary arteriovenous shunts using intravenous injections of $\mathrm{Kr}^{85}$ and T-1824 dye (abstract). J. clin. Invest. 1959, 28, 1006.

12. Jose, A. D., and Milnor, W. R. The demonstration of pulmonary arteriovenous shunts in normal human subjects, and their increase in certain disease states. J. clin. Invest. 1959, 38, 1915.

13. Braunwald, E., Long, R. T. L., and Morrow, A. G. Injections of radioactive krypton $\left(\mathrm{Kr}^{85}\right)$ solutions in the detection and localization of cardiac shunts (abstract). J. clin. Invest. 1959, 38, 990.

14. Long, R. T. L., Waldhausen, J. A., Cornell, W. P., and Sanders, R. J. Detection of right-to-left circulatory shunts: A new method utilizing injecttions of Krypton ${ }^{85}$. Proc. Soc. exp. Biol. (N. Y.) 1959, $102,456$.

15. Wilson, R. H., Ebert, R. V., Borden, C. W., Pearson, R. T., Johnson, R. S., Falk, A., and Dempsey, M. E. The determinations of blood flow through the nonventilated portions of the normal and diseased lung. Amer. Rev. Tuberc. 1953, 68, 177.

16. Briscoe, W. A., and Cournand, A. Uneven ventilation of normal and diseased lungs studied by an open-circuit method. J. appl. Physiol. 1959, 14, 284.

17. Briscoe, W. A. A method for dealing with data concerning uneven ventilation of the lung and its effects on blood gas transfer. J. appl. Physiol. 1959, 14, 291.

18. Briscoe, W. A. Comparison between alveolo arterial gradient predicted from mixing studies and the observed gradient. J. appl. Physiol. 1959, 14, 299.

19. Fluckiger, M. Vorkommen von trommelschlägelförmigen Fingerend-phalangen ohne chronische Veränderungen an der Lungen oder am Herzen. Wien. med. Wschr. 1884, 49, 1457. 
20. Keys, A., and Snell, A. M. Respiratory properties of the arterial blood in normal man and in patients with disease of the liver: Position of the oxygen dissociation curve. J. clin. Invest. 1938, 17, 59.

21. Jandl, J. H. The anemia of liver disease: Observations on its mechanism. J. clin. Invest. 1955, 34, 390.

22. Abelmann, W. H., Verstraeten, J. M., Frank, N. R., McNeely, W. F., and Kowalski, H. J. The alveolar-arterial oxygen pressure gradient in parenchymatous disease of the liver. Clin. Res. Proc. 1954, 2,47 .

23. Heinemann, H. O., Emirgil, C., and Mijnssen, J. P. Hyperventilation and arterial hypoxemia in cirrhosis of the liver. Amer. J. Med. 1960, 28, 239.
24. Rydell, R., and Hoffbauer, F. W. Multiple pulmonary arteriovenous fistulas in juvenile cirrhosis. Amer. J. Med. 1956, 21, 450.

25. McIndoe, A. H. Vascular lesions of portal cirrhosis. Arch. Path. (Chicago) 1928, 5, 23.

26. Schoenmackers, J., and Vieten, H. Porto-cavale und portopulmonale Anastamosen im postmortalen Portogramm. Fortschr. Röntgens 1953, 79, 488.

27. Calabresi, P., and Abelmann, W. H. Porto-caval and porto-pulmonary anastomoses in Laennec's cirrhosis and in heart failure. J. clin. Invest. 1957, 36, 1257.

28. Smythe, C. McC., Fitzpatrick H. F., and Blakemore, A. H. Studies of portal venous oxygen content in unanesthetized man (abstract). J. clin. Invest. 1951. 30, 674 . 